\title{
In-place HEPA filter testing by the sodium flame method
}

\author{
Zhenzhong Zhang*, Feng Jiang \\ Institute of Nuclear and New Energy Technology, Tsinghua University, P.R.China \\ *To whom correspondence may be addressed: Tel.: 86-10-62797365-8000; E-mail: zhangzz@ tsinghua.edu.cn.
}

\section{Introduction}

High-efficiency particulate air (HEPA) filters can be used to protect people and the environment from toxic and harmful gas and particles. Three steps must be performed prior to HEPA filter application: filter media testing, filter testing, and in-place filter testing (ASME N510, 2007; ASME N511, 2007; IEST-RP-CC001.5, 2009; IEST-RP-CC021.3, 2009). In HEPA filter testing, HEPA filters are tested individually, whereas in filter media testing, the filter media are tested roll by roll. Meanwhile, in-place testing of the HEPA filter is usually conducted in the following instances: acceptance test before a new cleaning system is brought into operation to test whether the filtration efficiency satisfies the design value, the filter has any damages, the end face has leaks, or whether the cleaning system can work on schedule or not; regular supervision and testing the system running process for periodical performance check; acceptance test after the old filters are replaced with new filters for purposes similar to those in the first instance; and supplementary testing for any probable adverse effects on the functional capability of the filters, such as the intrusion of water or other materials, painting, fire, or chemical release, etc. (ASME N510, 2007; ASME N511, 2007; RG1.52, 2012).

At present, three methods are primarily adopted for in-place filter testing: the dioctyl phthalate (DOP) method, sodium fluorescence method, and sodium flame method. The DOP method involves the generation of DOP aerosol by a Laskin nozzle generator or a thermal generator, measurement of the mass concentration of the DOP in the upstream and downstream by using an aerosol photometer, and calculation of filtration efficiency (MIL-STD-282, 1956; IEST-RP-001.5, 2009). The DOP method is widely used in filter efficiency testing because of its ease of operation. Because DOP has potentially toxic (Calley et al.,1966; Oishi and Hiraga, 1980; Gangolli, 1982; Wyrobek et al., 1983; Agarwal et al., 1985; Seed, 1992), some materials such as poly-alpha-olefin (PAO) and di-2-ethylhexyl-phthalate (DEHS) can be adopted for DOP testing, which eliminates hidden occupational hazards (HSDB, 2007; US-EPA, 2007; IEST-RP-CC001.5, 2009; RG1.52, 2012). In China, the sodium fluorescence method has been widely implemented in nuclear power plants since the adoption of this technique by the Daya Bay Nuclear Power Plant. However, the sodium fluorescence method is not the most advanced technology, considering its failure to accomplish in-place leak location testing. In the sodium fluorescence method, sodium fluorescence aerosol is produced by spraying a sodium fluorescence aqueous solution and subsequently sampling and analyzing the aerosol by using a fluorescence spectrophotometer in the laboratory (AFNOR NFX-44-011, 1972; Mei, 2008). Given that the efficiency testing of both the HEPA filter and the filter media adhere to the sodium flame method (GB/T6165, 2008), the sodium flame method can also be employed in in-place filter efficiency testing.

Both DOP and sodium flame methods can simultaneously determine in-place total efficiency and leak location testing because these techniques use an aerosol photometer and a sodium flame photometer, respectively, as online measurement tools. Therefore, compared with the sodium fluorescence method, these methods exhibit several advantages in terms of testing time and leak 
location. The present study elaborates on the sodium flame method used for in-place HEPA filter testing.

\section{Experimental method}

An efficiency testing method should include aerosol generation and aerosol measurement. In filter media testing and filter testing, $\mathrm{NaCl}$ aerosol is produced by spraying the $\mathrm{NaCl}$ aqueous solution and drying the droplet. This spraying-type sodium flame method only produces $\mathrm{NaCl}$ aerosol at $0.6 \mathrm{~g} / \mathrm{min}$. However, in in-place filter testing, a large amount of $\mathrm{NaCl}$ aerosol is needed, The spraying-type method is apparently inappropriate; thus, a new burning-type sodium flame method is adopted. The latter technique can generate $\mathrm{NaCl}$ aerosol at a rate of at least $4 \mathrm{~g} / \mathrm{min}$. The $\mathrm{NaCl}$ measurement approach is similar to the technique used in testing filter and filter media efficiencies.

\subsection{Aerosol generation}

\subsubsection{Principle}

Salt bar consists of chemically pure $\mathrm{NaCl}$, magnesium carbonate $\left(\mathrm{MgCO}_{3}\right)$, and methylcellulose, and has a uniform diameter. In testing, the salt bar is placed on a gear device and delivered into the flame produced by liquefied petroleum gas (LPG) burned in oxygen at a constant speed. At high temperatures, the methylcellulose volatilizes completely, $\mathrm{MgCO}_{3}$ decomposes into $\mathrm{CO}_{2}$ and $\mathrm{MgO}, \mathrm{CO}_{2}$ is released into the atmosphere, and $\mathrm{MgO}$ remains as the support protecting the melted $\mathrm{NaCl}$ from a splashdown and produces as much $\mathrm{NaCl}$ vapor as possible. The $\mathrm{NaCl}$ in the salt bar finally forms $\mathrm{NaCl}$ aerosol used as challenge aerosol for in-place HEPA filter testing by melting, evaporation, and condensation.

\subsubsection{Structure}

The aerosol generator is composed of an aerosol burner and a gear device. The melting point of $\mathrm{NaCl}$ is $1440{ }^{\circ} \mathrm{C}$. An annular burner shown in Figure 1 is expected to produce a flame warmer than $2000^{\circ} \mathrm{C}$. High temperature can adequately evaporate a salt bar into $\mathrm{NaCl}$ vapor. In relatively cold air, vapor suddenly condenses and forms $\mathrm{NaCl}$ particles. The burner should be designed such that it can continuously and steadily produce aerosol.

The gear device allows the salt bar to pass through the flame at a particular speed. The component consists of a micro motor, a set of speed change gears, as well as driving and driven rollers. The salt bar is placed between the two rollers, shifted forward by friction.

\subsubsection{Composition of the salt bar}

The composition of the salt bar significantly affects the continuous and steady production of $\mathrm{NaCl}$ aerosol. The salt bar must meet the following requirements:

(1) The salt bar exhibits sufficient strength, performs consistently, and is not easily deformed during shaping, stoving, storage, and burning;

(2) The salt bar can sufficiently evaporate and form $\mathrm{NaCl}$ aerosol by condensation; and

(3) The salt bar has a regular shape and a composition of uniform mixing.

\subsubsection{Inflammable gas}

The inflammable gas used to burn the salt bar should meet the following criteria:

(1) The calorific value per unit volume is large;

(2) The flame temperature of the inflammable gas is high;

(3) Reduced oxygen requirement leads to improved performance;

(4) The probability of gas explosion is low; and

(5) The gas can be carried easily. 


\subsection{Aerosol measurement}

\subsubsection{Principle}

$\mathrm{NaCl}$ aerosol measurement uses flame photometry. In principle, the challenge element is excited by an excitation light source, the flame. A photoelectric detection system is then used to measure the characteristic radiation intensity of the excited element and perform quantitative elementary analysis. The relation between light intensity and element concentration can be expressed as the

$$
I=A c B
$$

where I is the light intensity; $\mathrm{c}$ is the concentration; A is related to sample evaporation and excitation processes, and sample composition, among others; and $\mathrm{B}$ is the self-absorption coefficient associated with line absorption. Within certain ranges of concentration, A and B have constant values. One of the basic quantitative spectrometric analysis formulas is called the Cyber-Rome golden formula given in Equation (1).

For the element sodium, the wavelength of the excited characteristic line is $589 \mathrm{~nm}$. Therefore, it can obtain a corresponding $\mathrm{NaCl}$ mass concentration to measure the intensity of 589 nm yellow light.

The sodium flame photometer, which measures $\mathrm{NaCl}$ aerosol, consists of a burner, a photoelectric transducer, and a photoelectric measurement device (also called a microcurrent measurement device).

Sodium in $\mathrm{NaCl}$ is completely excited in the burner. The excited light intensity is converted into photocurrent in the photoelectric transducer. The microcurrent signal is measured in the photoelectric measurement device. The current exhibits a good relationship with the $\mathrm{NaCl}$ mass concentration, which requires calibration.

The filter filtration efficiency can be obtained by the following equation:

$$
\eta=\frac{c_{u}-c_{d}}{c_{u}} \times 100 \%
$$

where $c_{u}$ and $c_{d}$ represent the $\mathrm{NaCl}$ mass concentrations of the upstream and the downstream of the challenge filter, respectively; $c_{u}$ is related to the upstream photocurrent (also called the initial photocurrent); and $c_{d}$ is obtained by subtracting the background photocurrent from the downstream photocurrent. The relationship between the $\mathrm{NaCl}$ mass concentration and the photocurrent is obtained by photometer calibration.

\subsubsection{Hydrogen burner}

A hydrogen burner consists of the following: top, middle, and lower sleeves; glass sleeve; inflammable gas (hydrogen) and sampling air inlet tube; bend flange; and gas hood. Figure 2 illustrates the parts comprising the device. Hydrogen and sampling air flow rates are two key factors considered in measuring precision and the measurable range.

The hydrogen flow rate can strongly influence the background photocurrent of the photometer. A one-time increase in flow rate causes the photocurrent to increase multiple times. An extremely low hydrogen flow rate cannot sufficiently excite the $\mathrm{NaCl}$ particle, resulting in inaccurate measurement. An extremely high flow rate causes an extremely high flame temperature, thereby damaging the glass sleeve and resulting in silver film peeling. Thus, the hydrogen flow rate must be determined to achieve flame stability and a high ratio of initial to background photocurrents. 
Sampling air is another important factor affecting hydrogen burning and $\mathrm{NaCl}$ excitation. This process supplies sufficient oxygen to support complete hydrogen combustion.

\subsubsection{Photoelectric transducer}

A photoelectric transducer consists of an enclosure, a convex lens, a neutral density filter, a sodium interference filter, and a photomultiplier. This device translates an optical signal into a current signal.

The convex lens converts a point source into a parallel light and enhances the luminous flux. The neutral density filter protects the photomultiplier from strong light. When the aerosol concentration is high and the light is relatively intense, the intensity can be reduced several times to satisfy the requirement of the photomultiplier. A sodium interference filter is used to filter other light with different wavelengths, allowing only sodium light to pass through.

In this study, a Model CR110 photomultiplier (Beijing Hamamatsu Photon Technology Co., Ltd.) is used. The photomultiplier has an anode dark current of $2 \mathrm{nA}$ and meets the lowest current signal requirement of $10 \mathrm{nA}$.

\subsubsection{Photoelectric measuring device}

The excited $\mathrm{NaCl}$ particles can produce the characteristic spectrum of $589 \mathrm{~nm}$ and yield a weak current signal by using the photomultiplier. A homemade photoelectric measuring device can be used to measure the current signal ranging from $10 \mathrm{nA}$ to $25 \mu \mathrm{A}$.

Figure 3 presents the schematic of the photoelectric measuring device. This device is calibrated using a DM3058 digital multimeter (RIGOL, 2009).

\section{Results and discussion}

\subsection{Aerosol burner structure}

The spray angle of the burner can influence the evaporation ratio of $\mathrm{NaCl}$. The experimental result is plotted in Figure 4. The evaporation ratio reaches its highest value when the spray angle is $60^{\circ}$. The stability of the flame decreases when the angle is reduced. The reason is when the spray angle is bigger than $60^{\circ}$, the outside part of salt bar is completely burned and become salt vapor, while the inside part of salt bar is still salt block, so the evaporation ratio is relatively lower. If the spray angle is too small, typically less than $45^{\circ}$, the salt bar is very easy to be burn off because of over concentrated fire. By using a similar evaluation methodology, other burner parameters are determined: the aerosol burner has 12 spray holes with a diameter of $14 \mathrm{~mm}$, the distance between the centers of the spray hole and the burner is $13 \mathrm{~mm}$, and the diameter of the center hole of the burner is $12 \mathrm{~mm}$.

\subsection{Inflammable gas type}

Several types of inflammable gases and their properties are listed in Table 1. The acetylene-oxygen flame exhibits the highest temperature, and LPG has the largest calorific value. In terms of safety, LPG has no tempering phenomenon and the LPG container has a smaller volume compared with that of acetylene. Thus, LPG is more appropriate for in-place filter testing.

\subsection{Dust production rate and evaporation ratio}

The evaporation ratio and the dust production rate are two key factors affecting aerosol generation, which are determined using the orthogonal experimental design (Zhu et al., 2013).

The four major parameters are speed of delivery, $\mathrm{NaCl}$ percentage in the salt bar, diameter of the salt bar, and LPG flow rate. Each parameter has three optional values listed in Table 2.

The experimental optimal cases are listed in Table 3.

The values of the research indexes and the ranges are listed in Tables 4 and $5 . K_{i}$ is the sum of 
the evaporation ratio or the dust production rate at the $\mathrm{i}$ level, and $\mathrm{k}_{\mathrm{i}}$ is the average of $\mathrm{K}_{\mathrm{i}}$. These values show that the order of factors influencing the evaporation ratio is $\mathrm{A}>\mathrm{D}>\mathrm{B}>\mathrm{C}$, and the order for the dust production rate is $\mathrm{A}>\mathrm{C}>\mathrm{B}>\mathrm{D}$. Thus, the optimal case is $\mathrm{A}_{3} \mathrm{~B}_{2} \mathrm{C}_{1} \mathrm{D}_{1}$; that is, the speed of delivery is $49 \mathrm{~mm} / \mathrm{min}$, the $\mathrm{NaCl}$ percentage in the salt bar is $78 \%$, the diameter of the salt bar is $12.5 \mathrm{~mm}$, and the LPG flow rate is $3.8 \mathrm{l} / \mathrm{min}$.

\section{4 $\mathrm{NaCl}$ aerosol size distribution}

After parameters such as the burner structure, composition of salt bar, and type of inflammable gas are determined, the $\mathrm{NaCl}$ size distribution is evaluated using a Model DMPS3071 aerosol size distribution analysis apparatus (TSI Inc.). The dust production rate exceeds $4 \mathrm{~g} / \mathrm{min}$. The size distribution of the $\mathrm{NaCl}$ particles has a mass mean diameter of $0.41 \mu \mathrm{m}$, with a geometric standard deviation of 2.32. The measured values across different seasons are plotted in Figure 5. The graph shows good stability and consistency.

\subsection{Hydrogen and sampling air flow rates}

The photocurrent values during hydrogen burning are plotted in Figure 6. Photocurrent begins to stabilize when hydrogen has burned for 20 minutes.

Figure 7 shows the curve of the hydrogen flow rate as well as the initial and background light currents. At a flow rate of $200 \mathrm{ml} / \mathrm{min}$, the highest ratio of the initial and the background light currents is achieved, and the flame temperature remains moderate, given that the flow rate is not extremely high.

Figure 8 shows that at a combustion-supporting air flow rate lower than $1.51 / \mathrm{min}$, the fluctuations of the initial and the background photocurrents are markedly larger. Thus, the flow rate of $2.0 \mathrm{l} / \mathrm{min}$ is confirmed to support hydrogen burning.

\subsection{System stability testing}

$\mathrm{MgO}$ is difficult to melt and easily falls off the surface of the salt bar every two minutes during salt bar burning. The moment of $\mathrm{MgO}$ falling off the salt bar may influence the initial $\mathrm{NaCl}$ aerosol concentration. The reading on the flame photometer may also fluctuate from 20 seconds to 30 seconds, and the measured values may be less than the normal value.

Figure 9 shows the variations in initial light intensity, which responds to the $\mathrm{NaCl}$ aerosol mass concentration every minute. Salt bars 1 and 2 have $\mathrm{NaCl}$ percentages of $80 \%$ and $75 \%$, respectively. Figure 11 indicates that the falling off phenomenon of $\mathrm{MgO}$ exerts no influence on the initial current value because of the uniform mixing of $\mathrm{NaCl}$ aerosol with dilution air in the challenge cleaning system.

\subsection{Calibration of $\mathrm{NaCl}$ aerosol concentration}

The highest system flow rate designed is $60000 \mathrm{~m}^{3} / \mathrm{h}$, with the assumption that the dust production rate is $4 \mathrm{~g} / \mathrm{min}$ and the $\mathrm{NaCl}$ aerosol concentration is $4 \mathrm{mg} / \mathrm{m}^{3}$. Accordingly, the present study calibrated the relationship between $\mathrm{NaCl}$ concentrations and photocurrent values within the concentration range of $25 \mathrm{ng} / \mathrm{m}^{3}$ to $13 \mathrm{mg} / \mathrm{m}^{3}$. This range allows the testing efficiency to exceed 99.995\%. For the lower system flow rate, the dust production rate can be adjusted to meet the requirements of the sodium flame photometer.

The calibration results are plotted in Figure 10. As indicated in the figure, the two challenge photometers exhibit good agreement. At low concentrations, the $\mathrm{NaCl}$ concentration exhibits a linear relationship with the photocurrent, whereas at high concentrations, the curve depicts a nonlinear relationship between the $\mathrm{NaCl}$ concentration and the photocurrent. This finding proves that the self-absorption coefficient $\mathrm{B}$ is lower than 1 in high-concentration ranges; the higher the 
concentration, the lower is the value of B.

\subsection{In-place testing}

Using the aerosol generation and measurement apparatus introduced in an earlier section, an air cleaning system in a waste plant that consists of 18 HEPA filters is tested. The system flow rate is $30000 \mathrm{~m}^{3} / \mathrm{h}$, and the $\mathrm{NaCl}$ concentration is $4 \mathrm{~g} / \mathrm{min}$. The upstream filter and the downstream filter are located in the cleaning room and the tube behind the blower, respectively. Total efficiency and leak location experiments are conducted in this study.

The initial total efficiency of the sodium flame method is only $85 \%$. Meanwhile, the desired value is $99.95 \%$. To accomplish the sodium fluorescence method, which is widely used by Chinese nuclear power plants, all of the 18 filters or related housings need to be replaced, and the total efficiency is tested until the desired efficiency is met. The experiment, which wastes time and resources, has to be performed repeatedly because the method only tests total efficiency and lacks a location testing function for in-place leak and thus, cannot locate the shortage. By contrast, the sodium flame method has a leak location testing function, which locates a reserved electric conduit hole on the vertical wall. This hole causes a short circuit in the cleaning room and allows a large amount of $\mathrm{NaCl}$ aerosol to escape from one side of the electric conduit

After the leak point is determined, a closed-cell sponge that is $2 \mathrm{~cm}$ deep is added on the filter house and clamped with one bolt. The total efficiency is shown to be $92 \%$, which is less than the desired value in the subsequent test.

The second test by leak probe scanning shows that the seal of the filter section has flaws that can lead by wrong placement of the filter housing during installation, as shown in Figure 11.

After all filters are replaced with Model YM-01 HEPA filters (Henan Hejing Cleaning Technology Co., Ltd), the added closed-cell sponge is replaced with a rubber band, and the joint is sealed with a rubber plaster and fiberglass filter media. The last test shows that the total efficiency reaches $99.96 \%$.

The case presented in this study is a special case. Nevertheless, the case illustrates the advantage of the sodium flame method, which cannot only attain the total efficiency of the filter but also accurately locate spot defects in the filter and the surrounding structure.

In addition, the sodium flame method has been successfully used in testing the HEPA filter in a $5 \mathrm{MW}$ low-temperature nuclear heating reactor and a $10 \mathrm{MW}$ high-temperature gas-cooled reactor-test module (HTR-10) in 1989 and 2000, respectively.

\section{Conclusion}

In this paper, the sodium flame method used mainly for in-place testing of HEPA filter was demonstrated, in which, a large quantity of $\mathrm{NaCl}$ aerosol was generated by burning special salt bar. Through theoretical analysis and experimental study of the method, the conclusions are summarized as follows.

(1) In aerosol producing experiment, some structure and operating parameters are determined by studying $\mathrm{NaCl}$ aerosol production rate and evaporation ratio, the spray angle is $60^{\circ}$, while the salt bar consist of $78 \%$ of $\mathrm{NaCl}$ and $22 \%$ of $\mathrm{MgCO} 3$ and methylcellulose and is $12.5 \mathrm{~mm}$ in length, LPG is used as inflammable gas, and the speed of gear device is $\underline{49 \mathrm{~mm} / \mathrm{min}}$.

(2) In aerosol measurement stage, measurement range and precision are defined as two key factors, the flow rates of LPG, sampling air and hydrogen flow rates are 3.81/min, 21/min and $200 \mathrm{ml} / \mathrm{min}$ respectively. 
(3) Finally, a waste plant case application is analyzed to illustrate the applicability, stability and continuity of burning type sodium flame method for in-place filter testing.

\author{
Acknowledgment \\ This work was financially supported by National Science Foundation of China (Grants \\ $\underline{50608044}$ and 50978154) and Beijing Natural Science Foundation (Grant 8142023).
}

\title{
References
}

AFNOR NFX-44-011. (1972). Cleaning devices-method of measuring filter efficiency using a uranine (sodium fluorescence) aerosol. French: Association Francaise de Normalisation.

Agarwal, D.K., Lawrence, W.H., Nunez, L.J., \& Autian, J. (1985). Mutagenicity evaluation of phthalic acid esters and metabolites in Salmonella typhimurium cultures. Journal of Toxicology and Environmental Health. 16,61-69.

ASME N510. (2007). Testing of nuclear air-treatment systems. American Society of Mechanical Engineers. New York, NY.

ASME N511. (2007). In-service testing of nuclear air treatment, heating, ventilating, and air-conditioning system. American Society of Mechanical Engineers. New York, NY.

Calley, D., Autian, J., \& Guess, W.L. (1966). Toxicology of a series of phthalate esters. Journal of Pharmaceutical Sciences. 55,158-162.

Gangolli, S.D. (1982). Testicular effects of phthalate esters. Environmental Health Perspectives. 45, 77-84.

GB/T6165. (2008). Test methed of the performance of high efficiency particulate air filter-Efficiency and risistance. Beijing: China Standards Press.

HSDB. (2007). Hazardous substances data bank: deithylene glycol. National Library of Medicine.

IEST-RP-CC001.5. (2009). HEPA and ULPA filters. Institute of Environmental Sciences and Technology.

IEST-RP-CC021.3. (2009). Testing HEPA and ULPA filter media. Institute of Environmental Sciences and Technology.

Mei, Y. (2008). Sodium fluorescence method and apparatus for on-site test of nuclear HEPA filtering. Nuclear Techniques. 31:546-550.

MLD-STD-282. (1956). Filter units, protective clothing, gas-mask components and related products: performance test methods. Department of Defense, USA.

Oishi, S., \& Hiraga, K. (1980). Testicular atrophy induced by phthalic acid esters: effect on testosterone and zinc concentrations. Toxicology and Applied Pharmacology. 53,35-41.

RG 1.52. (2012). Design, inspection, and testing criteria for air filtration and adsorption units of post-accident engineered-safety-feature atmosphere cleanup systems in light-water-cooled nuclear power plants. U.S. Nuclear Regulatory Commission. Washington, DC.

RIGOL. (2009). DM3058 digital multimeter manual. Beijing.

Seed, J.L. (1992). Mutagenic activity of phtalata esters in bactreial liquid suspension assays. Environmental Health Perspectives. 45, 111-114.

US-EPA, I. (2007). Integrated Risk Information System: Ethylene glycol. US-EPA.

Wyrobek, A.J., Gordon, L.A., Burkhart, J.G., Francis, M.W., Kapp, R.W., Letz, G., Malling, H.V., Topham, J.C., \& Whorton, M.D. (1983). An evaluation of the mouse sperm morphology test and 
other sperm tests in nonhuman mammals. A report of the U.S. Environmental Protection Agency Gene-Tox Program. Mutation Research. 115,1-72.

Zhu, J.J., Chew, D.A.S., Lv, S.N., \& Wu, W.W. (2013). Optimization method for building envelope design to minimize carbon emissions of building operational energy consumption using orthogonal experimental design (OED). Habitat International. 37,148-154.

\section{List of graphics}

Figure 1. Schematic of the annular burner

Figure 2. Schematic of the hydrogen burner

Figure 3. Schematic of the photoelectric measuring device

Figure 4. Relationship between the evaporation ratio of $\mathrm{NaCl}$ aerosol mass to $\mathrm{NaCl}$ content in the salt bar and the spray angle of the burner 
Figure 5. $\mathrm{NaCl}$ size distribution across different seasons

Figure 6. Experiment on hydrogen burning stability

Figure 7. Relationship of the hydrogen flow rate with the initial and the background current values

Figure 8. Relationship of the sampling air flow rate with the initial and the background current values

Figure 9. Initial photocurrent variations along with time

Figure 10. Relationship between the $\mathrm{NaCl}$ mass concentration and the photocurrent

Figure 11. Leak locations of HEPA filter installation

\section{List of Tables}

Table 1. Parameters of some inflammable gases

Table 2. Optional values of four major parameters influencing dust production rate and evaporation ratio

Table 3. Experimental results in different cases

Table 4. Experimental analysis of the evaporation ratio 
Table 5. Experimental analysis of the dust production rate 
Table 1. Parameters of some inflammable gases

\begin{tabular}{ccc}
\hline Inflammable gas & Calorific value $\left(\mathrm{kcal} / \mathrm{m}^{3}\right)$ & Flame temperature $\left({ }^{\circ} \mathrm{C}\right)$ \\
\hline Liquefied petroleum gas & 21200 & 2100 to 2800 \\
Acetylene & 12000 & 3150 \\
Propane & 2800 & 2850 \\
Coal gas & 5000 & 2100 \\
Marsh gas & 7900 & 2000 \\
\hline
\end{tabular}

Table 2. Optional values of four major parameters influencing dust production rate and evaporation ratio

\begin{tabular}{ccccc}
\hline Number & $\begin{array}{c}\text { Factor A } \\
\text { (Speed of } \\
\text { delivery, } \\
\text { mm/min) }\end{array}$ & $\begin{array}{c}\text { Factor B } \\
\text { (NaCl percentage } \\
\text { in salt bar, \%) }\end{array}$ & $\begin{array}{c}\text { Factor C } \\
\text { (Diameter of salt } \\
\text { bar, mm) }\end{array}$ & $\begin{array}{c}\text { Factor D } \\
\text { (LPG flow rate, } \\
1 / \text { min) }\end{array}$ \\
\hline 1 & 30 & 75 & 12.5 & 3.8 \\
2 & 39 & 78 & 11.5 & 4.2 \\
3 & 49 & 80 & 11.0 & 4.5 \\
\hline
\end{tabular}

Table 3. Experimental results in different cases

\begin{tabular}{cccc}
\hline Number & Case & Evaporation ratio & Dust production rate \\
\hline 1 & $\mathrm{~A}_{1} \mathrm{~B}_{1} \mathrm{C}_{3} \mathrm{D}_{2}$ & 88.67 & 2.46 \\
2 & $\mathrm{~A}_{1} \mathrm{~B}_{2} \mathrm{C}_{1} \mathrm{D}_{1}$ & 97.50 & 3.75 \\
3 & $\mathrm{~A}_{1} \mathrm{~B}_{3} \mathrm{C}_{2} \mathrm{D}_{3}$ & 88.33 & 2.90 \\
4 & $\mathrm{~A}_{2} \mathrm{~B}_{1} \mathrm{C}_{2} \mathrm{D}_{1}$ & 83.67 & 3.01 \\
5 & $\mathrm{~A}_{2} \mathrm{~B}_{2} \mathrm{C}_{3} \mathrm{D}_{3}$ & 84.83 & 2.64 \\
6 & $\mathrm{~A}_{2} \mathrm{~B}_{3} \mathrm{C}_{1} \mathrm{D}_{2}$ & 70.33 & 3.46 \\
7 & $\mathrm{~A}_{3} \mathrm{~B}_{1} \mathrm{C}_{1} \mathrm{D}_{2}$ & 73.67 & 4.20 \\
8 & $\mathrm{~A}_{3} \mathrm{~B}_{2} \mathrm{C}_{2} \mathrm{D}_{3}$ & 87.00 & 4.65 \\
9 & $\mathrm{~A}_{3} \mathrm{~B}_{3} \mathrm{C}_{3} \mathrm{D}_{1}$ & 89.00 & 4.04 \\
\hline
\end{tabular}

Table 4. Experimental analysis of the evaporation ratio

\begin{tabular}{ccccc}
\hline & $\mathrm{A}$ & $\mathrm{B}$ & $\mathrm{C}$ & $\mathrm{D}$ \\
\hline $\mathrm{K}_{1}$ & 274.50 & 246.01 & 241.44 & 270.17 \\
$\mathrm{~K}_{2}$ & 238.83 & 269.33 & 259.00 & 246.00 \\
$\mathrm{~K}_{3}$ & 249.67 & 247.66 & 262.50 & 246.83 \\
$\mathrm{k}_{1}$ & 91.50 & 82.00 & 80.43 & 90.05 \\
$\mathrm{k}_{2}$ & 76.61 & 89.73 & 86.33 & 82.00 \\
$\mathrm{k}_{3}$ & 83.22 & 82.55 & 87.50 & 82.28 \\
Range R & 35.67 & 23.32 & 21.06 & 24.17 \\
\hline
\end{tabular}

Table 5. Experimental analysis of the dust production rate

\begin{tabular}{ccccc}
\hline & $\mathrm{A}$ & $\mathrm{B}$ & $\mathrm{C}$ & $\mathrm{D}$ \\
\hline $\mathrm{K}_{1}$ & 9.11 & 9.67 & 11.41 & 10.80 \\
$\mathrm{~K}_{2}$ & 9.11 & 11.04 & 10.58 & 10.57 \\
\hline
\end{tabular}




\begin{tabular}{ccccc}
\hline $\mathrm{K}_{3}$ & 12.89 & 10.36 & 9.14 & 9.74 \\
$\mathrm{k}_{1}$ & 3.04 & 3.22 & 3.80 & 3.60 \\
$\mathrm{k}_{2}$ & 3.04 & 3.68 & 3.52 & 3.52 \\
$\mathrm{k}_{3}$ & 4.30 & 3.45 & 3.05 & 3.25 \\
Range $\mathrm{R}$ & 3.78 & 1.37 & 2.27 & 1.06 \\
\hline
\end{tabular}




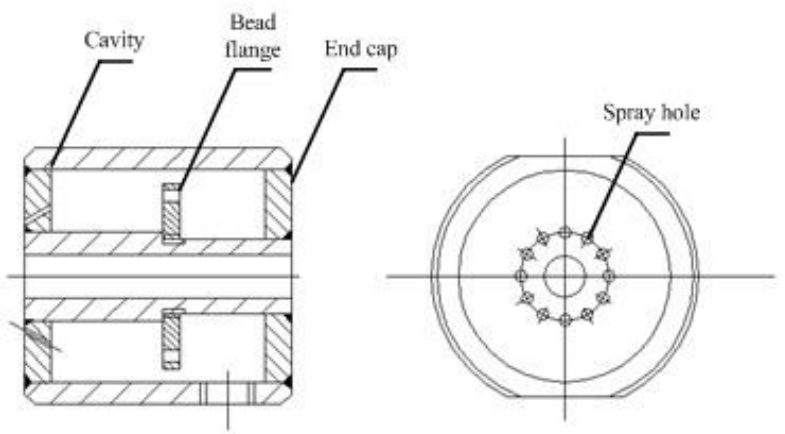

Figure 1. Schematic of the annular burner

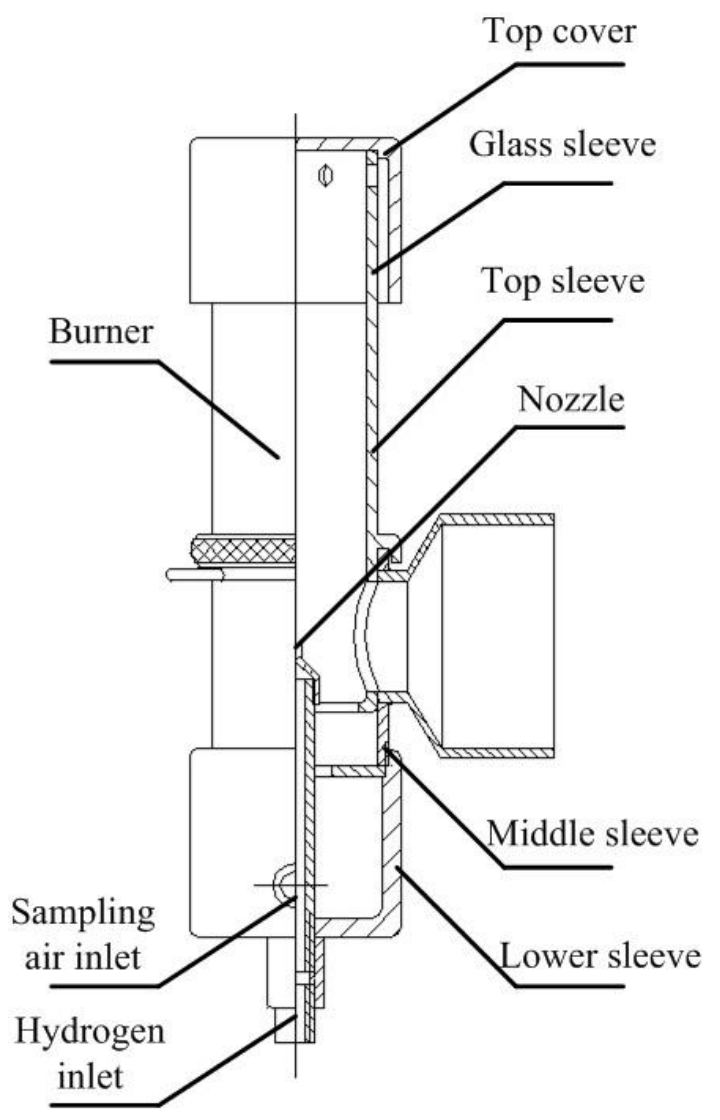

Figure 2. Schematic of the hydrogen burner

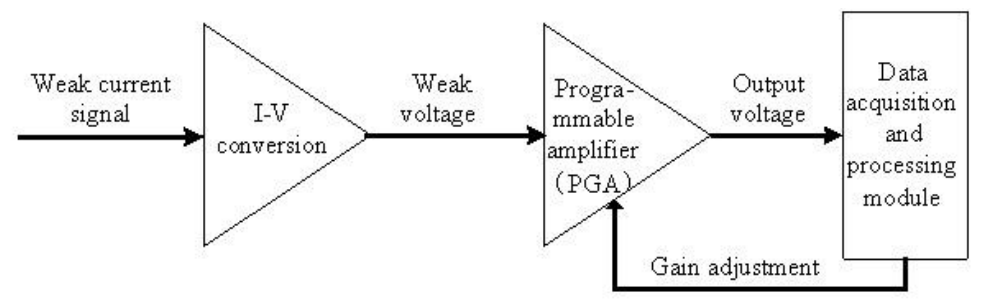

Figure 3. Schematic of the photoelectric measuring device 


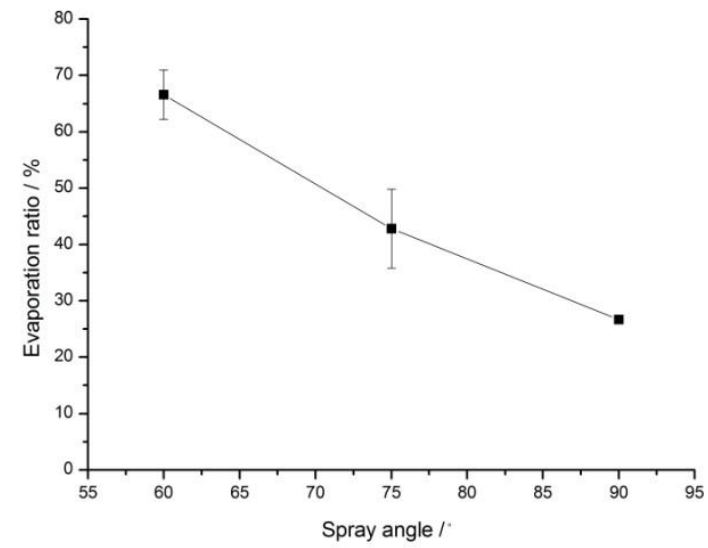

Figure 4. Relationship between the evaporation ratio of $\mathrm{NaCl}$ aerosol mass to $\mathrm{NaCl}$ content in the salt bar and the spray angle of the burner

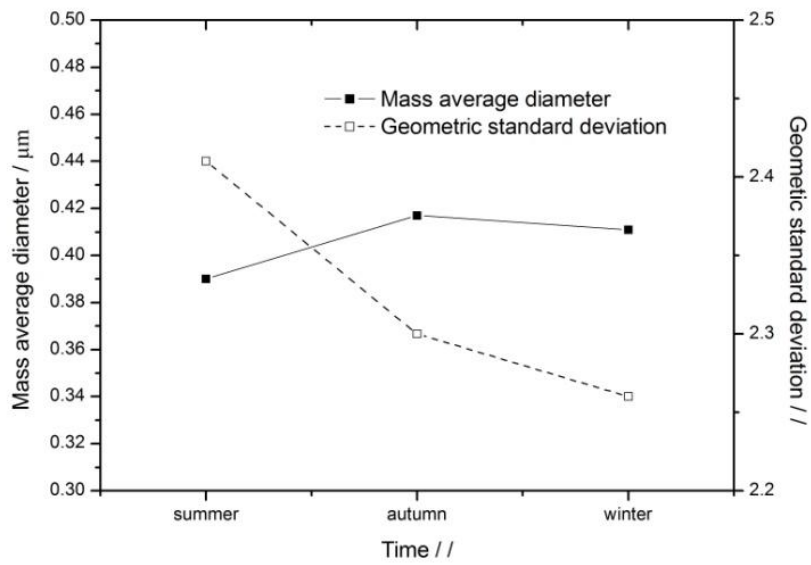

Figure 5. $\mathrm{NaCl}$ size distribution across different seasons

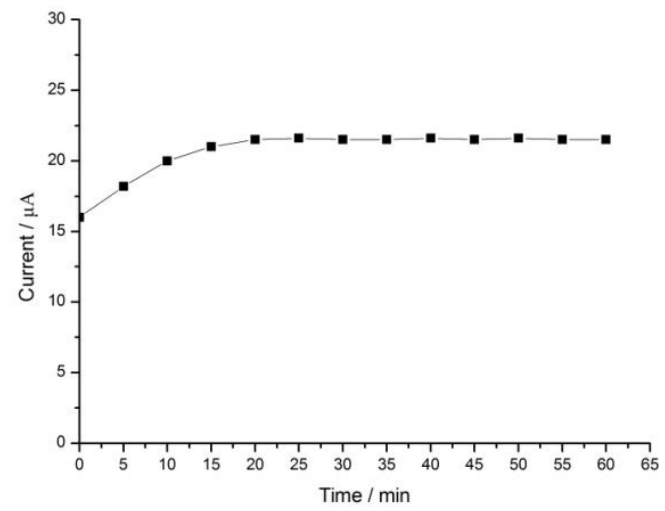

Figure 6. Experiment on hydrogen burning stability 


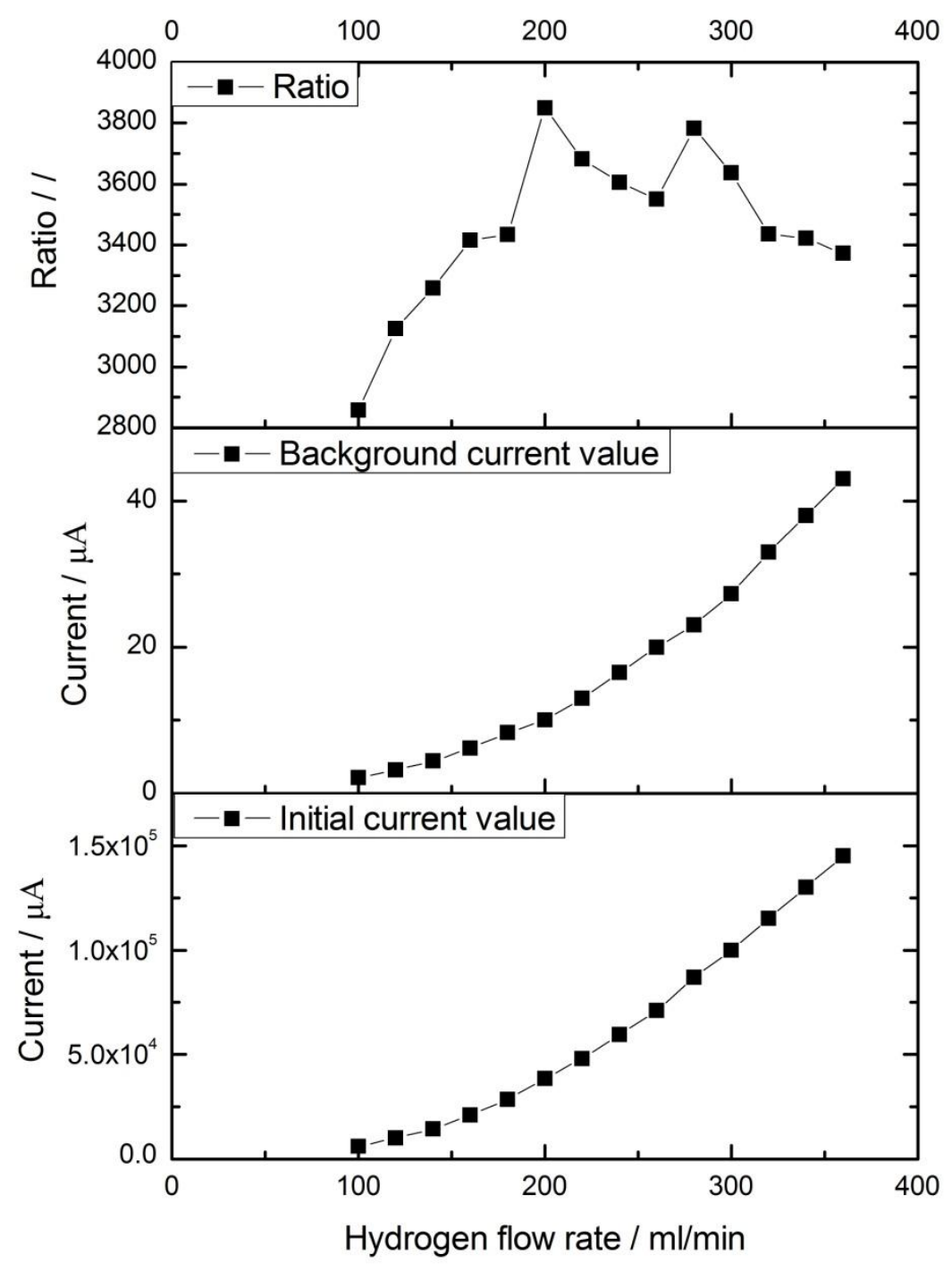

Figure 7. Relationship of the hydrogen flow rate with the initial and the background current values 


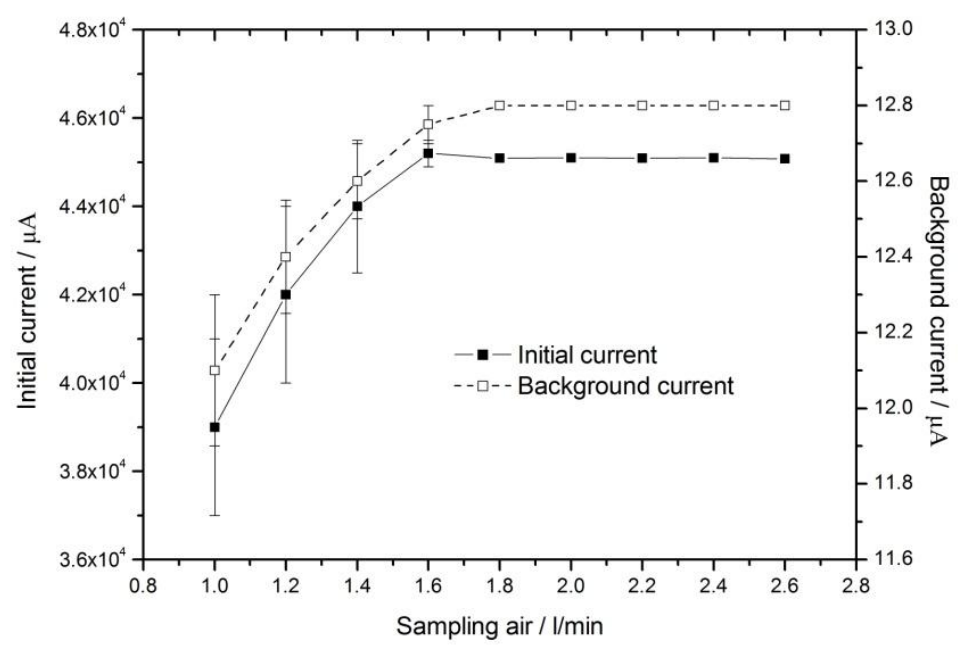

Figure 8. Relationship of the sampling air flow rate with the initial and the background current values

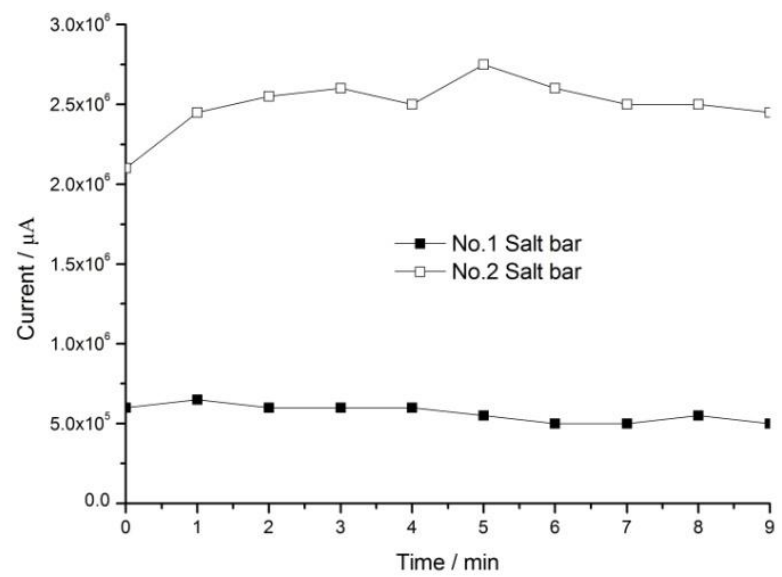

Figure 9. Initial photocurrent variations along with time

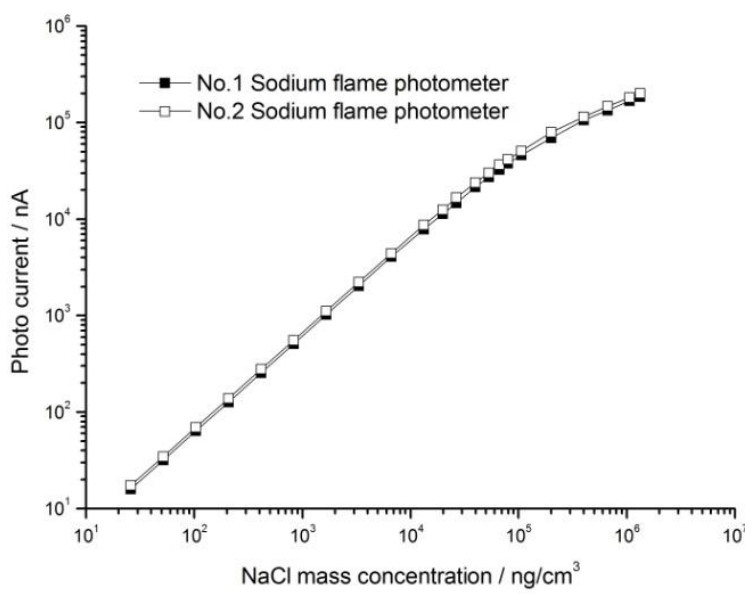

Figure 10. Relationship between the $\mathrm{NaCl}$ mass concentration and the photocurrent 


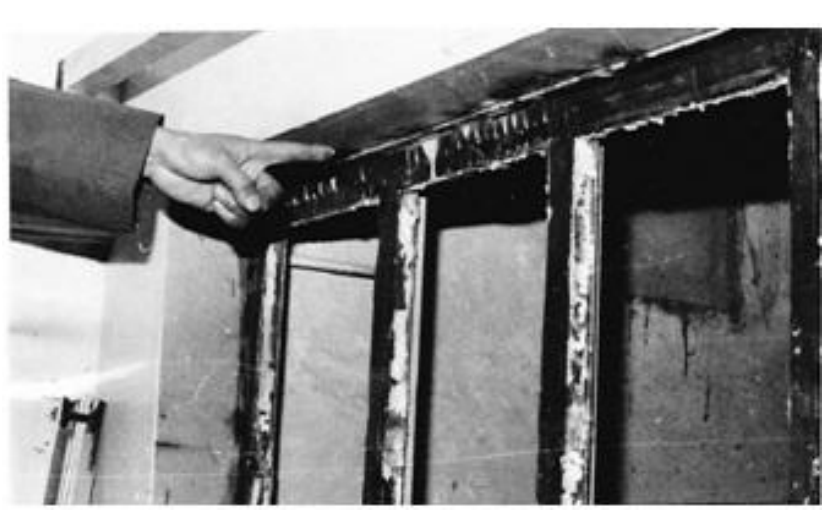

Figure 11. Leak locations of HEPA filter installation 


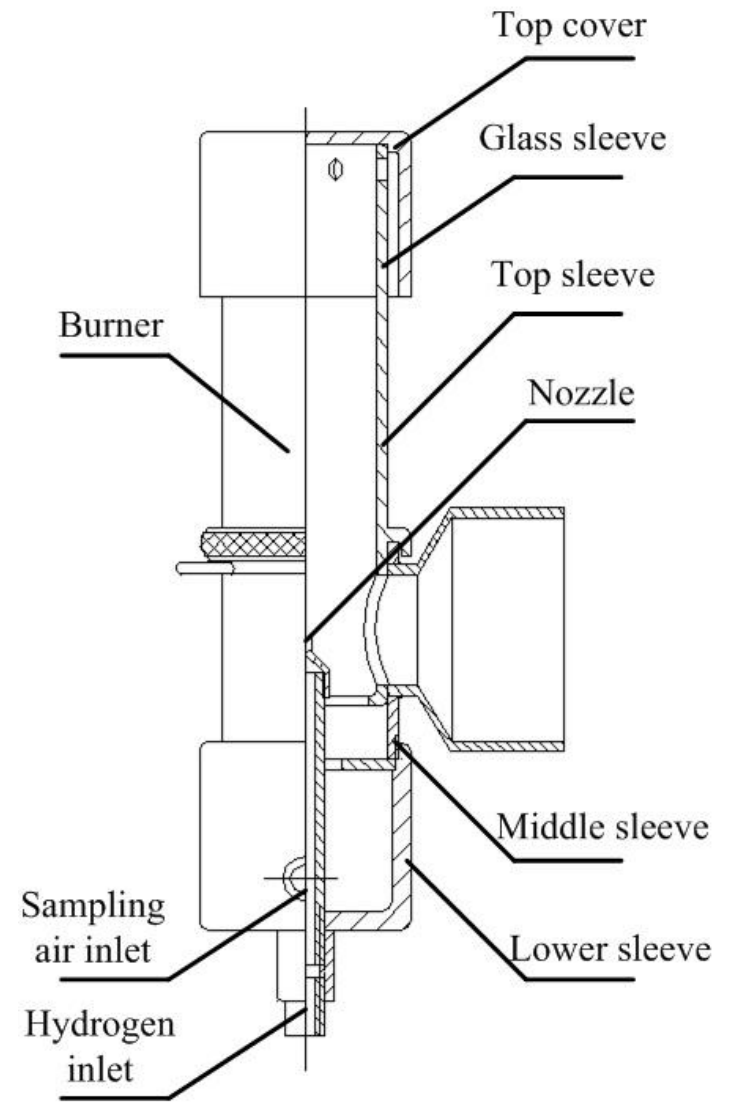

